\title{
DESCRIÇÃO DE TRÊS ESPÉCIES NOVAS DE CHASMOCARCINUS RATHBUN (CRUSTACEA, DECAPODA, GONEPLACIDAE), DO LITORAL BRASILEIRO
}

\author{
Petrônio Alves Coelho Filho 1,2 \\ Petrônio Alves Coelho 1, 3
}

\begin{abstract}
Description of threE New SPECIES of CHASMocarcinus RathBun (CRUSTACEA, DeCaPoda, Goneplacidae), From Brazilian litoral. Chasmocarcinus arcuatus sp.n. from Amapá, Chasmocarcinus hirsutipes sp.n. from Pará and Chasmocarcinus meloi sp.n. from Alagoas, Brazil are described.

KEY WORDS. Crustacea, Brachyura, Goneplacidae, Chasmocarcinus
\end{abstract}

O gênero Chasmocarcinus foi erigido por RATHBUN (1898a) para agrupar duas novas espécies de caranguejos coletados pelo "Albatross", por ela denominadas C. typicus e C. obliquus, sendo parte do material da primeira espécie proveniente do litoral brasileiro. No mesmo ano (1898b), a autora descreveu C. latipes oriunda da Califórnia (Pacífico), e em 1900, C. cylindricus, com localidade tipo Porto Rico.

BOUVIER (1917) faz a descrição de uma nova espécie, C. rathbuni, apoiado em um exemplar coletado pelo "Hassler" no litoral do Rio Grande do Sul (Brasil).

RATHBUN (1931) descreve uma nova espécie, C. mississipiensis, encontrada na região do Golfo do México.

GARTH (1940) apresenta a descrição de uma nova espécie encontrada no Panamá (Oceano Pacífico): C. longipes.

RODRIGUES DA COSTA (1968) no seu trabalho sobre os Brachyura coletados nas costas brasileiras pelo "Calypso" em 1967, descreve a terceira espécie "brasileira" de Chasmocarcinus, C. peresi, com localidade tipo Abrolhos, Bahia, Brasil.

COELHO et al. (1980) estudando a biogeografia e a bionomia dos crustáceos decápodos do litoral equatorial brasileiro, mencionam a ocorrência de três espécies distintas de Chasmocarcinus (sp. B, sp. C e sp. D), desconhecidas até aquele momento para a ciência, classificando-as como guianenses, costeiras e vasícolas. CoElHo et al. (1986) fazem menção da existência de uma espécie desconhecida de Chasmocarcinus no litoral do Rio Grande do Norte (Brasil), a 47 metros de profundidade, em fundos de algas calcárias, e a denominaram de Chasmocarcinus sp. B.

1) Departamento de Oceanografia, Universidade Federal de Pernambuco. Avenida Arquitetura, Cidade Universitária, 50670-901 Recife, Pernambuco, Brasil.

E-mail: pacf@npd.ufpe.br

2) Bolsista da CAPES.

3) Bolsista do CNPq. 
FELDER \& RABALAIS (1986), estudando este gênero na Plataforma Continental do Golfo do México, descrevem uma nova espécie, $C$. chacei e redescrevem C. mississipiensis.

BARRETO et al. (1991, 1993), estudando os Brachyura da plataforma continental do Norte e Nordeste, registram a presença de quatro espécies distintas, porém desconhecidas até aquele momento, denominadas de Chasmocarcinus sp. A, sp. B, sp. C e sp. D.

P.A. Coelho \& P.A. Coelho Filho (observações pessoais) referem como ocorrendo no Brasil, as espécies C. peresi, C. rathbuni e C. typicus, além de quatro outras a serem descritas, correspondentes às citadas anteriormente por COELHO et al. 1980 e BARRETO et al. 1993.

O presente trabalho tem como objetivo a descrição de três espécies novas do gênero Chasmocarcinus, com localidades tipo no litoral brasileiro, denominadas anteriormente como Chasmocarcinus sp. A, sp. C e sp. D.

\section{MATERIAL E MÉTODOS}

Os espécimens estudados foram provenientes de várias expedições oceanográficas ocorridas entre 1962 e 1993, a saber: "Akaroa"; "Calypso"; "Canopus"; Navio Oceanográfico "Almirante Saldanha" com as comissões "Norte/ Nordeste I e II", "Pesca Norte I", "Geomar I, II e III", "Pavasas"; além de outras pequenas expedições de menor amplitude. Todo o material foi coligido através de arrastos de dragas ou redes de fundo.

As instituições onde estão depositados os exemplares e as expedições de coleta são representadas pelas seguintes abreviaturas: (MZUSP) Museu de Zoologia da Universidade de São Paulo; (DOUFPE) Departamento de Oceanografia da Universidade Federal de Pernambuco; (SAL) Navio Oceanográfico "Almirante Saldanha", várias comissões; (GM) Projeto Geomar I, II e III; (AKA) "Akaroa"; (CAN) "Canopus"; (CAL) "Calypso".

Foram usadas ainda convenções para designar o sexo e o estágio evolutivo dos espécimens: (M) para machos; (F) para fêmeas; (Fov) para fêmeas ovadas e (J) para jovens. Apenas as amostras contidas neste item é que possuem posição sistemática e identificação confirmada.

\section{RESULTADOS}

\section{Chasmocarcinus arcuatus sp.n.}

Figs $1-4$

Chasmocarcinus peresi Rodrigues da Costa 1968: 335 [em parte].

Chasmocarcinus sp. D. - Coelho et al. 1980: 39. - Barreto et al. 1993: 651.

Tipos. Holótipo: Macho, SAL\#2497 (DOUFPE534); Parátipos: GM\#179 (DOUFPE528); GM\#179 (DOUFPE529), SAL\#1793BII (DOUFPE531), SAL\# 2497 (DOUFPE535), SAL\#7628 (DOUFPE536). Maiores informações podem ser encontradas na tabela I. 

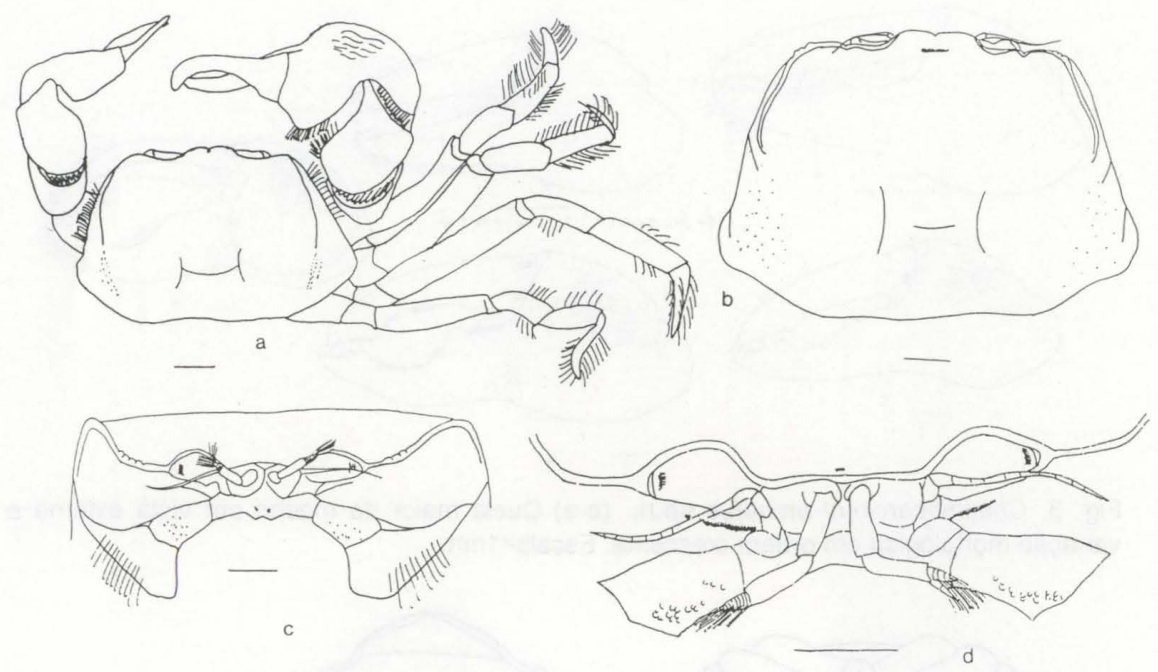

Fig. 1. Chasmocarcinus arcuatus sp.n., holótipo macho. (a) Vista dorsal; (b) detalhe dorsal da carapaça; (c) vista da região frontal da carapaça; (d) detalhe da região frontal. Escala=1 $\mathrm{mm}$.

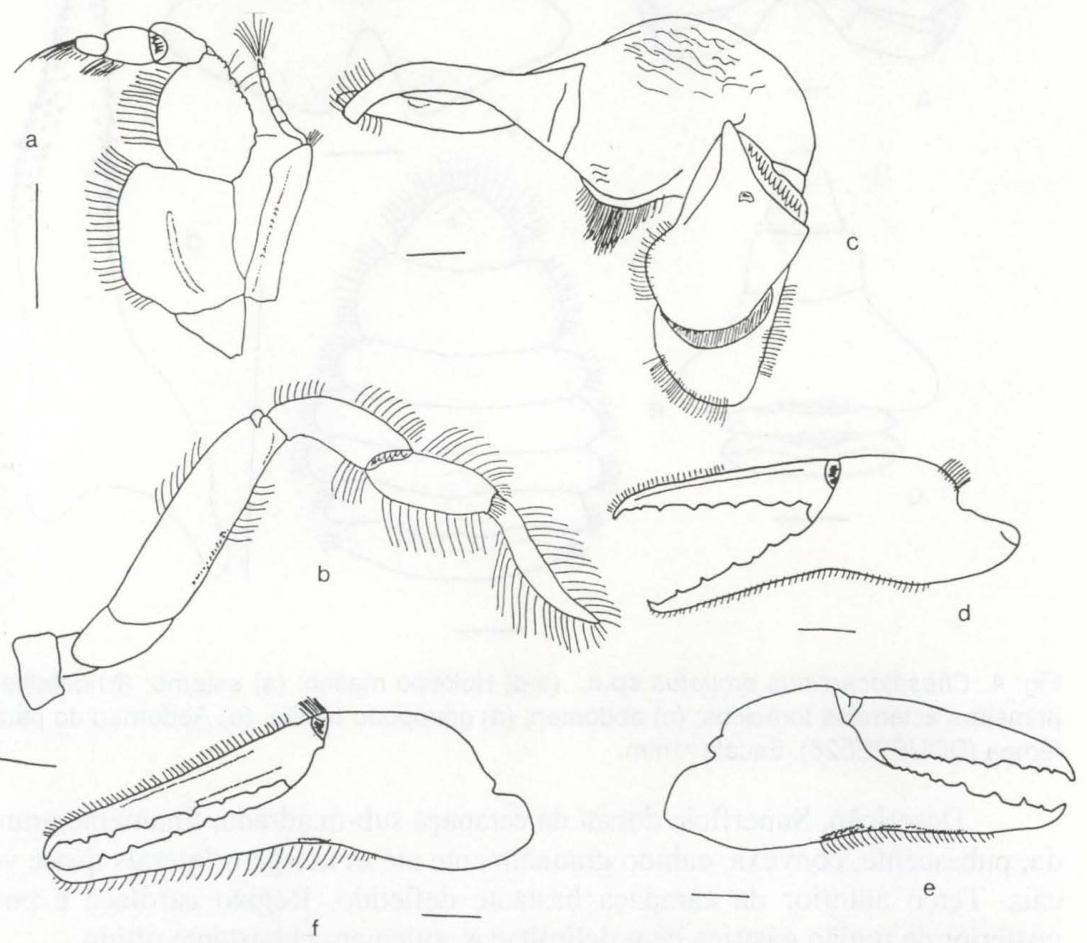

Fig. 2. Chasmocarcinus arcuatus sp.n.. (a-d) Holótipo macho: (a) maxilípodo externo esquerdo; (b) Quarta pata ambulatória direita; (c) vista dorsal do quelipodo maior; (d) quela menor em vista externa. (e-f) Parátipo fêmea (DOUFPE528): (e) quela maior em vista externa; (f) quela menor em vista externa. Escala $=1 \mathrm{~mm}$. 

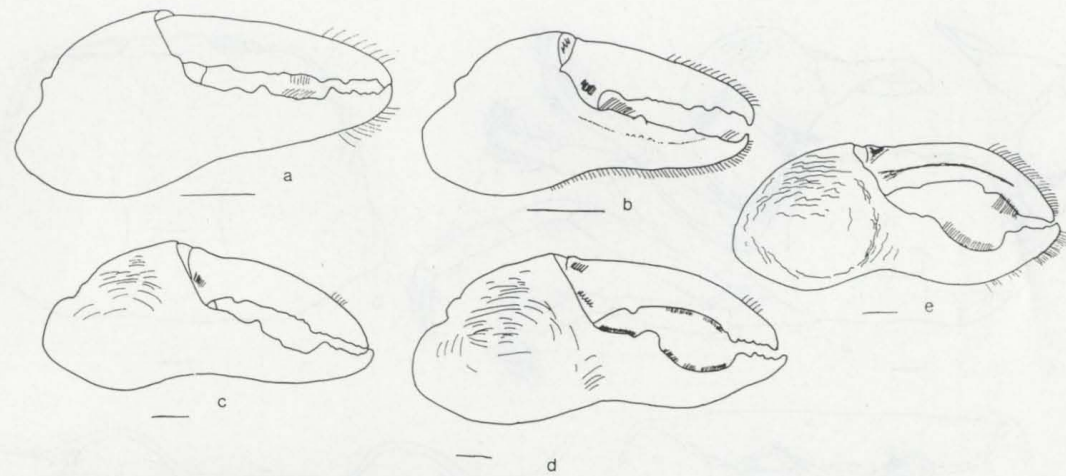

Fig. 3. Chasmocarcinus arcuatus sp.n.. (a-e) Quela maior do macho em vista externa e variação morfológica em ordem crescente. Escala $=1 \mathrm{~mm}$.

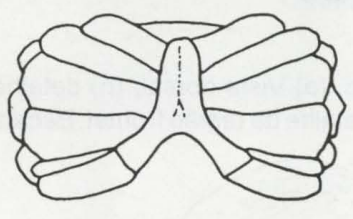

a
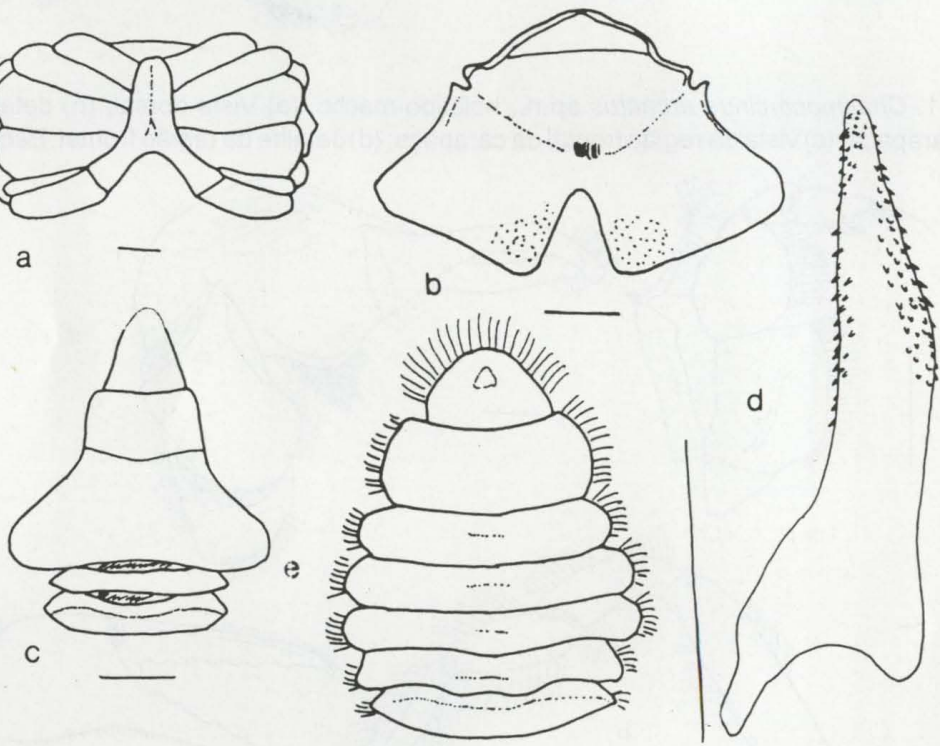

Fig. 4. Chasmocarcinus arcuatus sp.n.. (a-d) Holótipo macho: (a) esterno; (b) detalhe dos primeiros esternitos torácicos; (c) abdômen; (d) gonópodo direito. (e) Abdômen do parátipo fêmea (DOUFPE528). Escala=1mm.

Descrição. Superfície dorsal da carapaça sub-quadrada, finamente granulada, pubescente, convexa, caindo gradualmente até as margens laterais quase verticais. Terço anterior da carapaça bastante defletido. Região cardíaca e porção posterior da região gástrica bem delimitadas, sulco em $\mathrm{H}$ bastante nítido.

Metade anterior da margem lateral da carapaça com carena elevada, quase uma lâmina enfraquecendo-se anteriormente, dando a impressão de não chegar a tocar o ângulo orbital externo, com pequenos tubérculos próximos às margens; 
cerdas nas margens; do seu extremo posterior nasce um sulco bastante suave dirigindo-se para baixo e para frente, até a sutura lateral. Região póstero-lateral granulada.

Fronte com sulco mediano raso; margem anterior bilobada, lobos arredondados no lado externo, separados por ângulo muito aberto; largura da fronte pouco maior que a metade do bordo fronto-orbital.

Órbitas transversas e pequenas. Carena suborbital muito pequena e suave, quase inexistente; órbita cercando apenas a cavidade ocular.

Bordo fronto-orbital maior que metade da maior largura da carapaça.

Pedúnculo ocular curto e grosso.

Antênulas proeminentes; segundo artículo mais curto que os olhos, com finas cerdas; terceiro pouco afilado proximalmente, de tamanho semelhante ao segundo.

Flagelo das antenas alojado no hiato orbital interno; terceiro artículo não tocando a fronte.

Terceiros maxilípodos não fechando toda a cavidade bucal, cerdas esparsas próximo às margens dos segmentos; ísquio com sulco mediano pouco profundo, comprimento 1,25 vezes a largura; mero suboval, comprimento 1,25 vezes a largura, uma depressão próximo às margens interna e externa, margem externa com ângulo arredondado e granulado; largura do ísquio maior que a do mero; exopodito com elevação central granulada.

Quelípodos do macho muito diferentes. Direito maior e mais forte.

Quelípodo maior: carpo inerme, com o ângulo interno arredondado com uma franja de cerdas; margem superior com a metade proximal levemente erodida; cova próximo à margem superior distal; palma muito inflada, curta e larga, com a margem inferior muito convexa, área erodida na face externa; tufo de cerdas na face interna; dedos em eixos diferentes, com um grande hiato que corresponde a $2 / 3$ de sua extensão; pólex muito curvado para baixo, em forma de arco; comprimento igual ao do dáctilo; margem cortante com os dois terços basais lisos, interrompidos apenas por um dente isolado; terço distal denteado; dente proximal mais desenvolvido; dáctilo encurvado para baixo, em forma de arco; dois pequenos dentes nos primeiros dois terços, denteado no $1 / 3$ restante; comprimento uma vez e meia a altura da palma; porção distal da margem externa franjada de cerdas.

Quela menor do macho inerme, apenas com curtas cerdas; dedos levemente encurvados para baixo, finos, longos e achatados (em forma de pinça) com a margem cortante possuindo dentes isolados e regularmente espaçados; margens externas com uma fileira de cerdas, sendo que a do pólex prolonga-se um pouco na palma.

Quelas da fêmea semelhantes à quela menor do macho, porém com uma região granulada na margem do pólex prolongando-se um pouco na palma.

Patas ambulatórias com franjas de cerdas longas, principalmente, no carpo, própodo e dáctilo, sendo mais densos no primeiro e segundo pares; mero com cerdas curtas e esparsas, e levemente enrugado; dáctilo do primeiro ao terceiro pares achatado dorso-ventralmente, do quarto par achatado lateralmente e levemente encurvado para baixo e para fora, com pequenos grânulos na margem inferior do mero; comprimento da segunda pata ambulatória semelhante ao da terceira; mero do terceiro par de comprimento semelhante ao da carapaça. 
Esterno alargado, pubescente, levemente granulado; presença de uma placa suplementar entre o sétimo e oitavo esternitos; margem lateral externa entre o segundo e terceiro esternitos com uma fissura profunda; cavidade abdominal pubescente prolongando-se até pouco abaixo de uma depressão mediana entre o segundo e terceiro esternitos.

Abdômen do macho com cerdas, principalmente, nas margens do quinto e sexto segmentos e do télson; segundo segmento de largura semelhante ao primeiro; terceiro ao quinto fusionados; terceiro segmento o mais largo, com margem externa arredondada e elevação lateral. Abdômen da fềmea com sete segmentos, alargado no terceiro segmento, com longas cerdas nas margens, principalmente nos dois últimos segmentos, e pequena depressão central no último segmento.

Gonópodo do macho forte, afilado no terço distal; ornado com espinhos desenvolvidos.

Dimensão. Macho holótipo: comprimento da carapaça $(5,5 \mathrm{~mm})$, largura da carapaça $(6,83 \mathrm{~mm})$.

Localidade tipo. Brasil, Amapá, SAL\#2497, 31-V-1971, 400’N e 50³4’W, $50 \mathrm{~m} ; 25,33^{\circ} \mathrm{C}$ e $36,26 \%$; lama.

Outras referências. BRASIL: Amapá, Pará (BARRETO et al. 1993).

Material examinado. O material estudado encontra-se listado na tabela I.

Distribuição geográfica. Atlântico Ocidental do Amapá até o Espírito Santo (Brasil).

Habitat. Os dados sobre o habitat encontram-se na tabela II.

Reprodução. Foi encontrada uma fêmea ovada no mês de abril.

Etimologia. O nome científico deriva-se do fato desta espécie possuir os dedos da quela maior do macho em forma de arco, separados por um grande hiato.

Comentários. O hiato na distribuição desta espécie, entre o Pará e a Bahia, pode ser explicado pela ausência de condições ecológicas adequadas, na área em que ela não foi observada, ou seja, $C$. arcuatus distribui-se preferencialmente em locais de pouca profundidade, altas temperaturas e com fundos lamosos, rejeitando áreas com salinidade elevada e fundos mais arenosos ou organogênicos. Existe uma grande variação no tamanho e na forma do quelípodo maior do macho, tal como o aumento do hiato entre os dedos, do arqueamento dos dedos, além da redução dos dentes, possivelmente causados pelo aumento da maturidade sexual, porém esses processos dão-se de forma gradativa nas diferentes fases de desenvolvimento; contudo, observa-se sobretudo em todas as formas observadas, dois grandes dentes no pólex, palma com cerdas na face interna e área erodida na externa (Fig. 3).

\section{Chasmocarcinus hirsutipes sp.n.}

Figs 5-7

Chasmocarcinus sp. C. - COELHO et al. 1980: 39. - BARRETO et al. 1993: 651.

Tipos. Macho holótipo: SAL\#2476 (DOUFPE521); parátipos: GM\#046 (DOUFPE514), GM\#156 (DOUFPE517), SAL\#1765 (DOUFPE518; DOUFPE560) e SAL\#1988 (DOUFPE519). Maiores informações na tabela III. 
Tabela I. Lista do material examinado de Chasmocarcinus arcuatus sp.n.. (L) Lama, (A/L) areia+lama, (A) areia.

\begin{tabular}{|c|c|c|c|c|c|c|c|c|c|}
\hline Estaçăo & Data & Latitude & Longitude $\mathrm{F}$ & $\begin{array}{l}\text { Profundidade } \\
\text { (m) }\end{array}$ & $\begin{array}{l}\text { Temperatura } \\
\left({ }^{\circ} \mathrm{C}\right)\end{array}$ & $\begin{array}{c}\text { Salinidade } \\
(\%)\end{array}$ & Fundo & Material & Coleção \\
\hline CAL\#1823 & 12.II.62 & $17^{\circ} 56^{\prime} \mathrm{S}$ & $38^{\circ} 50^{\prime} \mathrm{W}$ & 24 & - & - & $A / L$ & $4 \mathrm{M}, 4 \mathrm{~F}$ & MZUSP8229 \\
\hline CAL\#1826 & 12.11.62 & $17^{\circ} 52,5^{\prime} \mathrm{S}$ & $38^{\circ} 49^{\prime} \mathrm{W}$ & 21 & - & - & $A / L$ & $1 \mathrm{M}$ & DOUFPE522 \\
\hline Esp. Santo & - & - & - & 39 & - & - & - & $1 \mathrm{M}$ & MZUSP6066 \\
\hline GM I Arrasto & - & - & - & - & - & - & - & $2 \mathrm{M}$ & DOUFPE523 \\
\hline GM\#156 & IV.71 & $1^{\circ} 52,5^{\prime} \mathrm{N}$ & $48^{\circ} 21^{\prime} \mathrm{W}$ & 44 & - & - & L & $9 \mathrm{M}, 7 \mathrm{~F}$ & DOUFPE524 \\
\hline GM\#158 & 25.IV.71 & $1^{\circ} 33^{\prime} \mathrm{N}$ & $48^{\circ} 48^{\prime} \mathrm{W}$ & $44-48$ & - & - & $\mathrm{L}$ & $1 \mathrm{~F}$ & DOUFPE525 \\
\hline GM\#164 & 27.IV.71 & $2^{\circ} 1,5^{\prime} \mathrm{N}$ & $48^{\circ} 28,9^{\prime} W$ & 53 & - & - & $\mathrm{L}$ & $11 \mathrm{M}, 12 \mathrm{~F}$ & DOUFPE526 \\
\hline GM\#165 & 27.IV.71 & $2^{\circ} 6,6^{\prime} \mathrm{N}$ & $48^{\circ} 24^{\prime} W$ & 51 & - & - & $\mathrm{L}$ & $2 F$ & DOUFPE527 \\
\hline GM\#179 & IV.71 & $4^{\circ} 32^{\prime} \mathrm{N}$ & $51^{\circ} 7,5^{\prime} \mathrm{W}$ & 63 & - & - & $\mathrm{L}$ & $1 \mathrm{~F}$ & DOUFPE528 \\
\hline GM\#179 & IV.71 & $4^{\circ} 32^{\prime} \mathrm{N}$ & $51^{\circ} 7,5^{\prime} \mathrm{W}$ & 63 & - & - & L & $3 \mathrm{M}, 8 \mathrm{~F}, 1 \mathrm{Fov}$ & DOUFPE529 \\
\hline GM\#192 & 07.V.71 & $3^{\circ} 24^{\prime} \mathrm{N}$ & $49^{\circ} 51,5^{\prime} \mathrm{W}$ & 70 & - & - & L & $3 M$ & DOUFPE530 \\
\hline SAL\#1793BII & 18.XI.67 & $4^{\circ} 13^{\prime} \mathrm{N}$ & $50^{\circ} 26^{\prime} \mathrm{W}$ & 75 & - & - & $\mathrm{A} / \mathrm{L}$ & $9 \mathrm{M}, 14 \mathrm{~F}$ & DOUFPE531 \\
\hline SAL\#1892 & 01.V.68 & $1^{\circ} 45^{\prime} \mathrm{N}$ & $48^{\circ} 18^{\prime} W$ & 56 & 27,66 & 35,67 & $A / L$ & $2 \mathrm{M}, 2 \mathrm{~F}$ & DOUFPE532 \\
\hline SAL\#2476 & 27.V.71 & $1^{\circ} 11^{\prime} \mathrm{N}$ & $45^{\circ} 55,5^{\prime} \mathrm{W}$ & 44 & 27,63 & 35,49 & A & $2 F$ & DOUFPE533 \\
\hline SAL\#2497 & 31.V.71 & $4^{\circ} \mathrm{N}$ & $50^{\circ} 34^{\prime} \mathrm{W}$ & 59 & 25,33 & 36,26 & $\mathrm{~L}$ & $1 \mathrm{M}$ & DOUFPE534 \\
\hline SAL\#2497 & 31.V.71 & $4^{\circ} \mathrm{N}$ & $50^{\circ} 34^{\prime} \mathrm{W}$ & 59 & 25,33 & 36,26 & L & $1 \mathrm{M}, 1 \mathrm{~F}$ & DOUFPE535 \\
\hline SAL\#7628 & 20.VIII. 87 & $1^{\circ} 19,5^{\prime} \mathrm{N}$ & $48^{\circ} 9,4^{\prime} W$ & 45 & 28,47 & 36,64 & A & $2 \mathrm{M}$ & DOUFPE536 \\
\hline
\end{tabular}

Tabela II. Dados sobre o habitat das três espécies novas de Chasmocarcinus Rathbun do Brasil. (L) Lama, (A/L) areia+lama, (A) areia, (O) organogênico.

\begin{tabular}{|c|c|c|c|c|c|c|c|c|c|c|}
\hline \multirow{2}{*}{ Espécie } & \multicolumn{2}{|c|}{ Profundidade (m) } & \multicolumn{2}{|c|}{ Temperatura $\left({ }^{\circ} \mathrm{C}\right)$} & \multicolumn{2}{|c|}{ Salinidade $(\% 0)$} & \multicolumn{4}{|c|}{ Tipo de fundo (\% de estações) } \\
\hline & Minimo & Máximo & Mínimo & Máximo & Minimo & Máximo & $\mathrm{L}$ & All & $A$ & 0 \\
\hline C. arcuatus & 21,00 & 75,00 & 25,33 & 28,47 & 35,49 & 36,64 & 54 & 31 & 15 & - \\
\hline C. hirsutipes & 24,00 & 77,00 & 27,37 & 28,24 & 35,49 & 36,48 & 33 & 22 & 45 & - \\
\hline C. meloi & 21,00 & 130,00 & 21,10 & 25,90 & 36,13 & 36,72 & 67 & - & - & 33 \\
\hline
\end{tabular}

Tabela III. Lista do material examinado de Chasmocarcinus hirsutipes sp.n.. (L) Lama, (A/L) areia+lama, (A) areia.

\begin{tabular}{|c|c|c|c|c|c|c|c|c|c|}
\hline Estaçăo & Data & Latitude & Longitude $\mathrm{F}$ & $\begin{array}{l}\text { Profundidade } \\
(\mathrm{m})\end{array}$ & $\begin{array}{l}\text { Temperatura } \\
\left({ }^{\circ} \mathrm{C}\right)\end{array}$ & $\begin{array}{c}\text { Salinidade } \\
(\% 0)\end{array}$ & Fundo & Material & Coleçăo \\
\hline GM\#034 & 07.VI.70 & $0^{\circ} 21 ' s$ & $46^{\circ} 58^{\prime} \mathrm{W}$ & 30 & - & - & A & $1 \mathrm{M}$ & DOUFPE513 \\
\hline GM\#046 & 09.VI.70 & $1^{\circ} 5^{\prime} \mathrm{N}$ & $47^{\circ} 42,4^{\prime} W$ & 63 & - & - & A & $2 \mathrm{M}$ & DOUFPE514 \\
\hline GM\#047 & 09.VI.70 & $0^{\circ} 37^{\prime} \mathrm{N}$ & $47^{\circ} 51^{\prime} \mathrm{W}$ & 43 & - & - & A & $1 \mathrm{~J}$ & DOUFPE515 \\
\hline GM\#097 & $11.1 X .70$ & $2^{\circ} 24,5^{\prime} \mathrm{N}$ & $48^{\circ} 38,5^{\prime} \mathrm{W}$ & 77 & - & - & $\mathrm{A} / \mathrm{L}$ & $1 F$ & DOUFPE516 \\
\hline GM\#156 & IV.71 & $1^{\circ} 52,5^{\prime} \mathrm{N}$ & $48^{\circ} 21^{\prime} W$ & 44 & - & - & $L$ & $2 \mathrm{M}, 2 \mathrm{~F}$ & DOUFPE517 \\
\hline SAL\#1765 & 12.XI.67 & $0^{\circ} 31 ' \mathrm{~N}$ & $47^{\circ} 49^{\prime} \mathrm{W}$ & 39 & 27,37 & 36,48 & A/L & $61 \mathrm{M}, 69 \mathrm{~F}$ & DOUFPE518 \\
\hline SAL\#1765 & 12.XI.67 & $0^{\circ} 311^{\prime} \mathrm{N}$ & $47^{\circ} 49^{\prime} \mathrm{W}$ & 39 & 27,37 & 36,48 & $\mathrm{~A} / \mathrm{L}$ & $1 \mathrm{M}$ & DOUFPE560 \\
\hline SAL\#1988 & 22. XI.68 & $0^{\circ} 26^{\prime} \mathrm{S}$ & $47^{\circ} 35,5^{\prime} \mathrm{W}$ & 24 & 28,24 & 35,68 & A & $1 \mathrm{M}, 5 \mathrm{~F}$ & DOUFPE519 \\
\hline SAL\#1993II & $23 . X 1.68$ & $2^{\circ} 10^{\prime} \mathrm{N}$ & $48^{\circ} 7^{\prime} \mathrm{W}$ & 49 & - & - & L & $2 \mathrm{M}, 1 \mathrm{~F}$ & DOUFPE520 \\
\hline SAL\#2476 & 27.V.71 & $1^{\circ} 11^{\prime} \mathrm{N}$ & $47^{\circ} 55,5^{\prime} \mathrm{W}$ & 44 & 27,63 & 35,49 & A & $1 \mathrm{M}$ & DOUFPE521 \\
\hline
\end{tabular}

Descrição. Carapaça sub-quadrada a sub-trapezoidal, levemente arredondada posteriormente, superfície dorsal finamente granulada, com cerdas longas espalhadas uniformemente, principalmente próximo às margens, convexa, caindo gradualmente até as paredes laterais quase verticais; terço anterior defletido; região gástrica e porção posterior da cardíaca bem marcadas; sulco em $\mathrm{H}$ bastante nítido. 


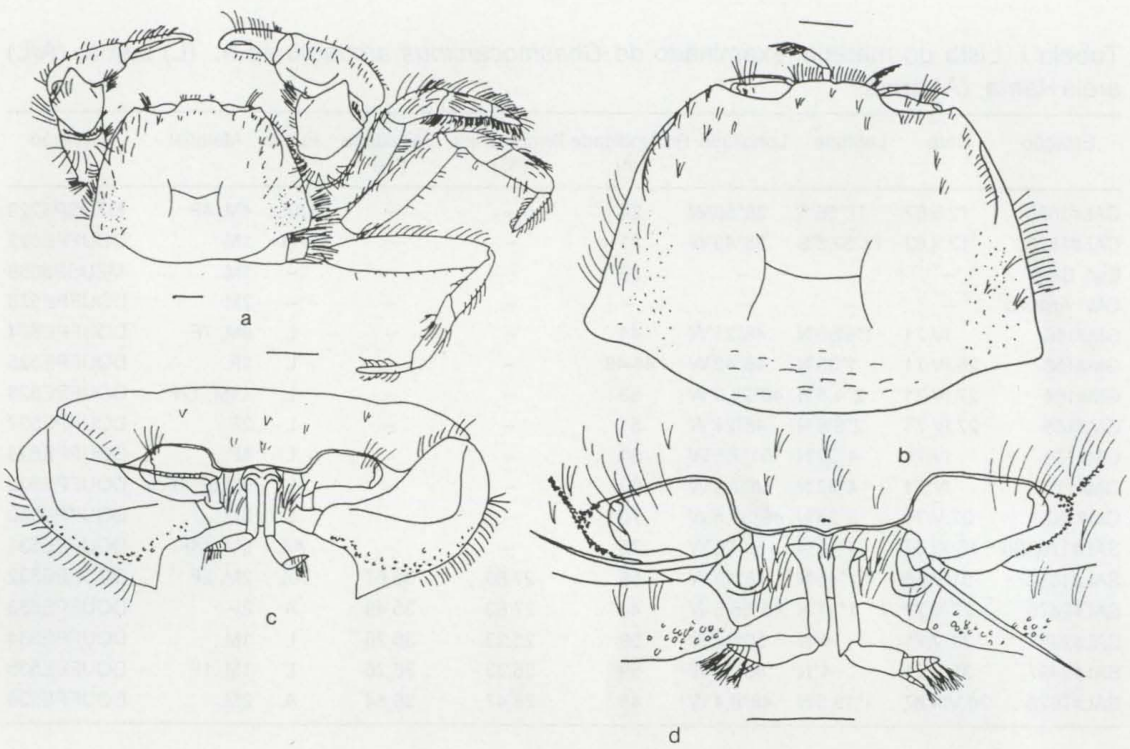

Fig. 5. Chasmocarcinus hirsutipes sp.n., holótipo macho. (a) Superficie dorsal (falta a quarta pata ambulatória); (b) detalhe dorsal da carapaça; (c) vista da região frontal; (d) detalhe da região frontal. Escala $=1 \mathrm{~mm}$.

Porção anterior da margem lateral marcada por uma carena baixa, formada por fileira de grânulos e cerdas por toda extensão; do seu extremo posterior parte um sulco que se dirige obliquamente para frente e para baixo até a sutura lateral.

Região frontal separada do restante da carapaça por uma depressão horizontal, localizada na altura das margens orbitais superiores. Fronte desprovida de sulco mediano; margem anterior inteira, quase transversal, com os cantos laterais arredondados; arqueamento côncavo mediano pouco perceptível ou inexistente; largura menor que a metade do bordo fronto-orbital.

Margens orbitais superiores obliquamente dirigidas para frente e para fora; carena suborbital bastante definida, granulada, indo além da região orbital onde encontra-se com a carena ântero-lateral; margens orbitais cercando duas áreas: uma cavidade em que o olho está encaixado, e uma outra rasa, margeando a cavidade ocular de lado e por baixo.

Bordo fronto-orbital maior que a metade da maior largura da carapaça.

Pedúnculo ocular alargado na base estreitando-se até a córnea. Olhos em toda extensão cobertos por cerdas moderadamente longas, principalmente sob a córnea.

Fosseta antenular e artículo basal das antênulas densamente cobertos por cerdas; antênulas proeminentes; segundo artículo cilíndrico com comprimento semelhante ao do olho, com poucos cerdas espaçadas; terceiro artículo cilíndrico, alargado abruptamente na porção distal, comprimento cerca de metade do artículo antecessor.

Antenas longas; pedúnculo cerca de três vezes o comprimento dos olhos; terceiro artículo tocando a margem frontal; alojado no hiato orbital interno. 


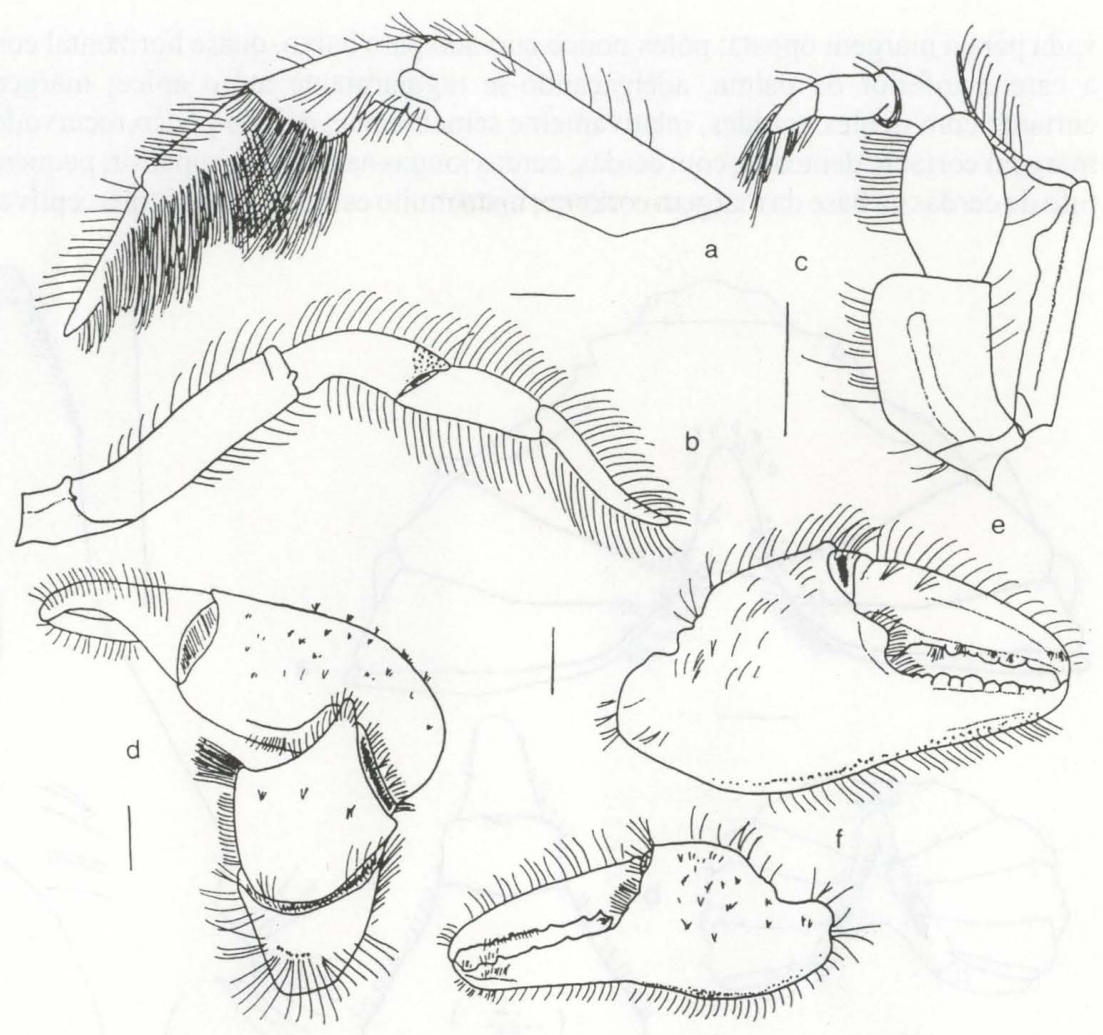

Fig. 6. Chasmocarcinus hirsutipes sp.n., holótipo macho. (a) Primeira pata ambulatória direita; (b) Quarta pata ambulatória direita; (c) maxilípodo externo esquerdo; (d) vista dorsal do quelípodo maior; (e) quela maior em vista externa; (f) quela menor em vista externa. Escala $=1 \mathrm{~mm}$.

Maxilípodos externos pubescentes, com cerdas localizadas principalmente nas margens internas dos segmentos, não fechando toda cavidade bucal; ísquio com comprimento maior que a largura máxima, com um sulco transversal suave; mero semi-oval, com o comprimento maior que uma vez e meia a largura; carpo, própodo e dáctilo pequenos e cilíndricos.

Quelípodos do macho diferentes; direito maior e mais forte.

Quelípodo maior: mero com a margem ventral levemente granulada e com cerdas; carpo pubescente, com cerdas longas nas suas margens; ângulo interno com um dente, geralmente em forma de quilha, maior no quelípodo menor, coberto por um tufo de cerdas; margem interna superior levemente granulada; palma curta, larga, e com cerdas; face anterior separada da face inferior por uma carena granulada, com uma fileira de cerdas prolongando-se no pólex; face interna desprovida de área com cerdas, dedos sulcados, levemente encurvados para dentro, com extremidade encur- 
vada para a margem oposta; pólex pouco curvado para baixo, quase horizontal com a carena inferior da palma, adelgaçando-se regularmente até o ápice; margem cortante com dentes grandes, relativamente semelhantes; dáctilo pouco recurvado; margem cortante denteada, com cerdas; cerdas longas na margem superior; pequeno tufo de cerdas na base da margem cortante; hiato muito estreito, quase imperceptível.

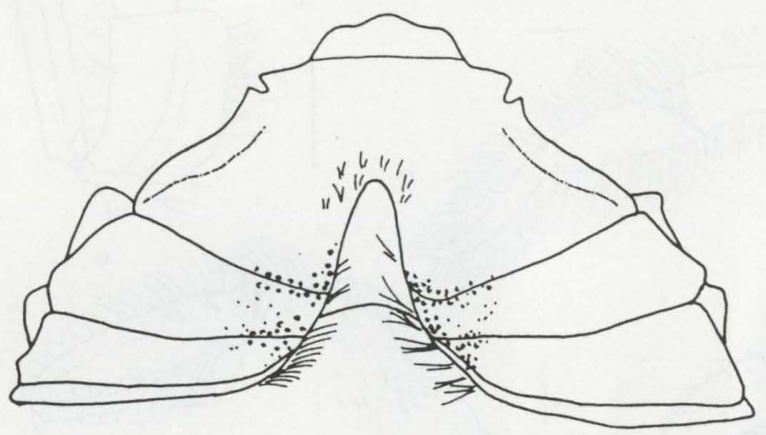

a
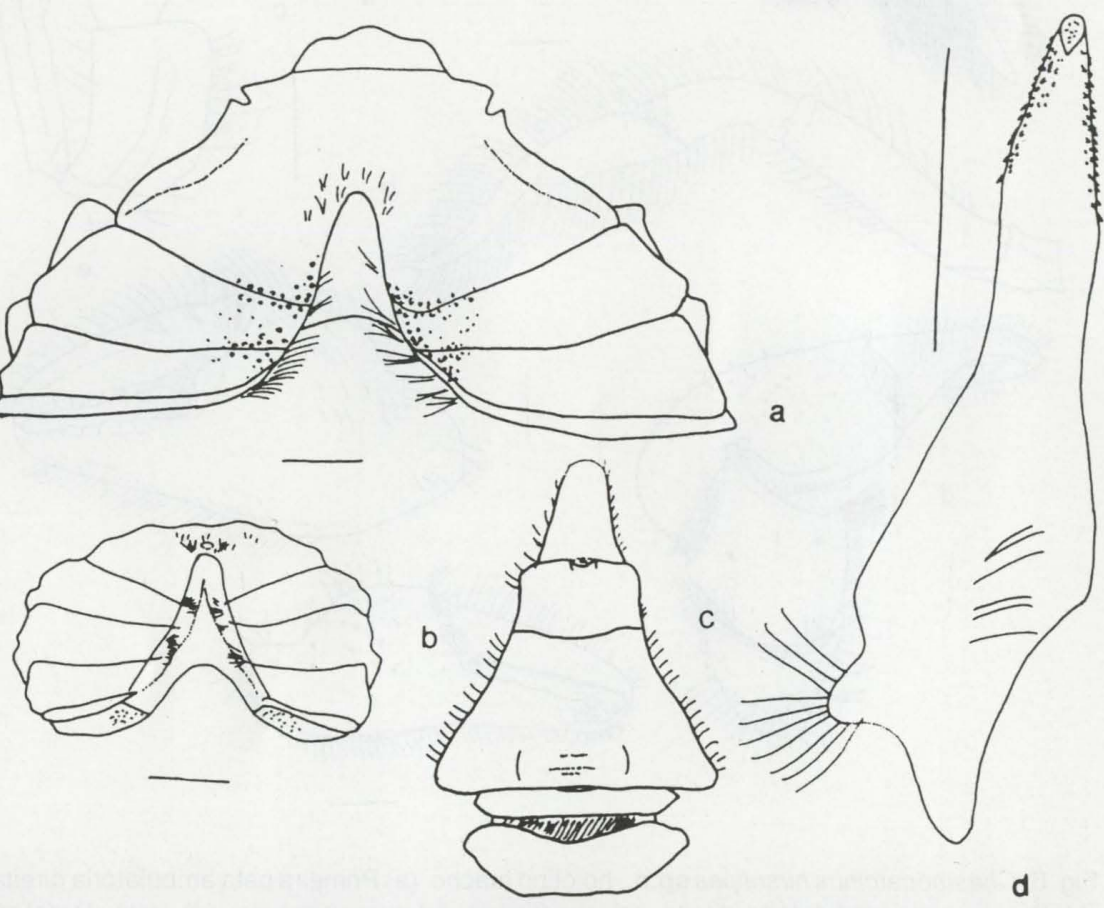

Fig. 7. Chasmocarcinus hirsutipes sp.n., holótipo macho. (a) Primeiros esternitos torácicos; (b) esterno; (c) abdômen; (d) gonópodo direito. Escala=1mm.

Quelípodo menor do macho semelhante a maior, porém mais fraco, com cerdas mais longas e em maior número; dedos mais finos com dentes da margem cortante menos desenvolvidos; pólex com cinco dentes bem salientes.

Quelípodos das fêmeas adultas semelhantes aos do macho; tubérculo do carpo mais desenvolvido.

Patas ambulatórias longas, finas e com cerdas; cerdas longas em todos os segmentos; primeiro par com a superfície ventral do carpo, própodo e dáctilo com tufos de cerdas longas e extraordinariamente densas, principalmente no par do lado direito; dáctilo do primeiro ao terceiro pares achatados ventralmente, do quarto achatado lateralmente e levemente encurvados para baixo; extremidade distal do carpo do quarto par granulado.

Esterno alargado, pubescente e levemente granulado; presença de grânulos 
agudos entre o terceiro, quarto e quinto esternitos; placa suplementar entre o sétimo e oitavo esternitos; cavidade abdominal indo até a sutura entre o segundo e terceiro esternitos, que apresenta uma depressão mediana e um profundo entalhe na margem lateral do esterno.

Abdômen do macho pubescente, estreito; primeiro segmento de largura semelhante ao segundo; terceiro segmento, o mais largo, fusionado ao quarto e quinto, com as margens não sinuosas, praticamente oblíquas; extremidade do terceiro segmento aguda, pouco arredondada; sexto com uma elevação central na margem distal; presença de cerdas próximo à margem do télson.

Gonópodo do Macho forte, porém afilado na sua porção mediana; pequenos espinhos na extremidade distal; cerdas perto da base.

Dimensão. Macho holótipo: comprimento da carapaça $(6,58 \mathrm{~mm})$, largura da carapaça (7,0mm).

Localidade tipo. Pará, Brasil; SAL\#2476, 25-V-1971, $01^{\circ} 11^{\prime} \mathrm{N}$ e 4755,5'W, 44 metros; $27,63^{\circ} \mathrm{C}$ e $35,49 \%$; areia.

Outras referências. BRASIL: Amapá, Pará (BARRETo et al. 1993).

Material examinado. O material estudado encontra-se na tabela III.

Distribuição geográfica. Amapá e Pará, Brasil.

Habitat. Os dados sobre o habitat encontram-se na tabela II.

Etimologia. O nome científico desta espécie relaciona-se com a presença de cerdas extremamente densas e longas na margem inferior do primeiro par de patas ambulatórias; hirsutus $=$ adjetivo: de cerdas longas, duras e espessas + pes $=$ substantivo: pé.

Comentários. Alguns indivíduos mal conservados possuem pouco ou quase nenhuma cerda no corpo, porém todos conservam a grande quantidade no primeiro par de patas ambulatórias. Observou-se também em alguns exemplares pequenas variações, tais como a fronte mais angulosa e a diminuição do tamanho do dente interno do carpo dos quelípodos.

\section{Chasmocarcinus meloi sp.n.}

Figs $8-9$

Chasmocarcinus sp A. - BARRETO et al. 1991: 291. - BARRETO et al. 1993: 651.

Tipos. Holótipo: Macho, AKA\#170 (DOUFPE503); parátipos: AKA\#076 (DOUFPE500), AKA\#087 (DOUFPE501), AKA\#170 (DOUFPE504), AKA\#173 (DOUFPE505), AKA\#177 (DOUFPE506), AKA\#178 (DOUFPE507), AKA\#181 (DOUFPE508) e AKA\#184 (DOUFPE509). Maiores informações na tabela IV.

Descrição. Carapaça sub-quadrada; superfície dorsal finamente granulada, pubescente, convexa, caindo gradualmente até as paredes laterais quase verticais; terço anterior defletido; região gástrica e porção posterior da cardíaca bem marcadas, sulco em $\mathrm{H}$ bastante forte.

Porção anterior da margem lateral marcada por forte carena com fileira de grânulos bastante agudos; a porção posterior da carapaça desprovida de carena, porém granulada. 


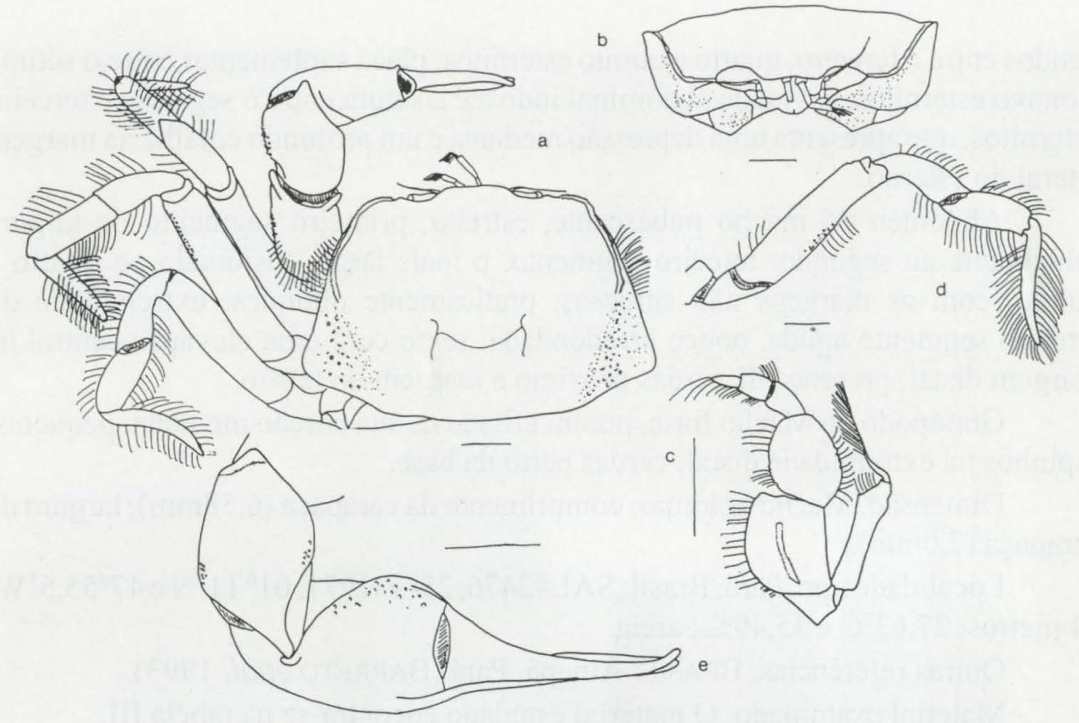

Fig. 8. Chasmocarcinus meloi sp.n., holótipo macho. (a) Superficie dorsal (falta a terceira pata ambulatória); (b) vista anterior da região frontal; (c) maxilipodo externo esquerdo; (d) quarta pata ambulatória direita; (e) quela e carpo do quelípodo maior em vista dorsal. Escala=1mm.
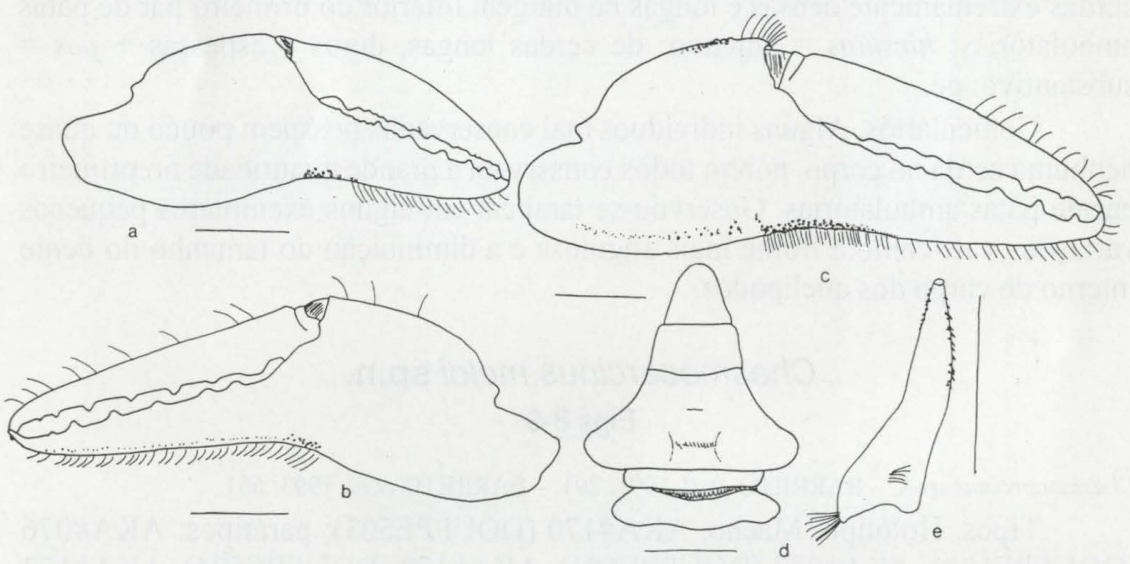

Fig. 9. Chasmocarcinus meloi sp.n.. (a-b, d-e) Holótipo macho: (a) quela maior em vista externa; (b) quela menor em vista externa; (d) abdômen; (e) gonópodo direito. (c) Parátipo fêmea (DOUFPE504) quela maior em vista externa. Escala $=1 \mathrm{~mm}$.

Fronte quase reta, larga, possuindo dois lobos separados por sulco mediano raso com ângulo muito aberto; largura da fronte correspondendo a $2 / 3$ da largura fronto-orbital.

Órbitas pequenas e transversais. Margens orbitais desprovidas de grânulos ou sulcos; carena sub-orbital quase imperceptível, permitindo considerar que as órbitas limitam apenas a cavidade orbital. Olhos pequenos. 
Tabela IV. Lista do material examinado de Chasmocarcinus meloi sp.n.. (L) Lama, (O) organogênico.

\begin{tabular}{|c|c|c|c|c|c|c|c|c|c|}
\hline Estaçăo & Data & Latitude & Longitude $F$ & $\begin{array}{l}\text { Profundidade } \\
\text { (m) }\end{array}$ & $\begin{array}{c}\text { Temperatura } \\
\left({ }^{\circ} \mathrm{C}\right)\end{array}$ & $\begin{array}{c}\text { Salinidade } \\
(\%)\end{array}$ & Fundo & Material & Coleçăo \\
\hline AKA\#076 & $4.1 \times .65$ & $10^{\circ} 2,71$ 'S & $35^{\circ} 58^{\prime} \mathrm{W}$ & 21 & 25,9 & 36,13 & O & $1 \mathrm{~F}$ & DOUFPE500 \\
\hline AKA\#087 & $3.1 X .65$ & $10^{\circ} 18,3$ 'S & $35^{\circ} 56,3^{\prime} \mathrm{W}$ & 54 & 25,6 & 36,71 & 0 & $1 \mathrm{~F}$ & DOUFPE501 \\
\hline AKA\#096 & $3.1 \times .65$ & $10^{\circ} 25,5$ 'S & $36^{\circ} 8,2^{\prime} \mathrm{W}$ & 23 & 25,6 & 36,72 & $\mathrm{~L}$ & $1 \mathrm{M}$ & DOUFPE502 \\
\hline AKA\#170 & 3.XII.65 & $10^{\circ} 33,7^{\prime} \mathrm{S}$ & $36^{\circ} 16,5^{\prime} \mathrm{W}$ & 50 & 22,8 & 36,53 & L & $1 \mathrm{M}$ & DOUFPE503 \\
\hline AKA\#170 & 3.X11. 65 & $10^{\circ} 33,7^{\prime} \mathrm{S}$ & $36^{\circ} 16,5^{\prime} \mathrm{W}$ & 50 & 22,8 & 36,53 & $L$ & $1 \mathrm{M}, 4 \mathrm{~F}$ & DOUFPE504 \\
\hline AKA\#173 & $3 . \times 11.65$ & $10^{\circ} 37^{\prime S}$ & $36^{\circ} 22,7^{\prime} \mathrm{W}$ & 80 & 23,4 & 36,64 & L & $1 \mathrm{~F}$ & DOUFPE505 \\
\hline AKA\#177 & 4.XII.65 & $10^{\circ} 37,9^{\prime} \mathrm{S}$ & $36^{\circ} 19,5^{\prime} \mathrm{W}$ & 108 & 22,4 & 36,49 & L & $1 \mathrm{~F}$ & DOUFPE506 \\
\hline AKA\#178 & 4.XII.65 & $10^{\circ} 37^{\prime} \mathrm{S}$ & $36^{\circ} 17,2^{\prime} \mathrm{W}$ & 76 & 22,3 & 36,45 & $L$ & $2 \mathrm{M}$ & DOUFPE507 \\
\hline AKA\#181 & 4.XII.65 & $10^{\circ} 38,15^{\prime} \mathrm{S}$ & $36^{\circ} 16^{\prime} \mathrm{W}$ & 130 & 21,1 & 36,31 & L & $2 F$ & DOUFPE508 \\
\hline AKA\#184 & 4.XII. 65 & $10^{\circ} 42^{\prime} \mathrm{S}$ & $36^{\circ} 22,5^{\prime} \mathrm{W}$ & 75 & 22,7 & 36,40 & 0 & $1 \mathrm{~F}$ & DOUFPE509 \\
\hline Arembebe/BA & $13.1 \times .93$ & - & - & - & - & - & - & $1 F$ & DOUFPE510 \\
\hline CEPEMAR & 25.V.93 & $12^{\circ} 52,4^{\prime} \mathrm{S}$ & $38^{\circ} 10,6^{\prime} \mathrm{W}$ & - & - & - & L & $2 \mathrm{~F}$ & DOUFPE511 \\
\hline CEPEMAR & 26.V.93 & $12^{\circ} 53,24^{\prime} \mathrm{S}$ & $38^{\circ} 15,8^{\prime} \mathrm{W}$ & - & - & - & $\mathrm{L}$ & $1 F$ & DOUFPE512 \\
\hline Maceió/AL & $23 . \times 87$ & - & - & $10-20$ & - & - & - & $1 F$ & MZUSP9342 \\
\hline SAL\#1817A & $28 . X 1.67$ & $2^{\circ} 7,9^{\prime} \mathrm{S}$ & $42^{\circ} 26,2^{\prime} \mathrm{W}$ & 73 & - & - & 0 & $1 \mathrm{~F}$ & MZUSP8562 \\
\hline
\end{tabular}

Bordo fronto-orbital quase igual a $2 / 3$ da largura da carapaça.

Antênulas proeminentes; artículo basal maciço, articulado pela superfície meso-dorsal com o segundo artículo; segundo e terceiro artículos alongados, de tamanho semelhantes, o terceiro mais subcilíndrico. Ramo dorsal mais robusto com quatro longos cerdas; ramo ventral um pouco maior e mais delgado, afinando-se até a extremidade distal.

Pedúnculo antenal alojado no hiato orbital interno; flagelo cerca de uma vez e meia o tamanho do olho; terceiro artículo tocando a fronte.

Terceiros maxilípodos não fechando toda a cavidade bucal; profundo sulco no ísquio, comprimento pouco maior que a largura; margem lateral externa e interna do mero granulada, comprimento cerca de 1,25 vezes a largura; largura do ísquio um pouco maior que a do mero; exopodito com o ângulo superior interno agudo; porção superior da margem externa sinuosa.

Quelípodos do macho diferentes, mas não muito; direito maior e mais forte.

Quelípodo maior: mero com faces inferior e superior granuladas e com uma fileira de longas cerdas; carpo inerme, com grânulos nos ângulos interno e externo; palma curta e larga, com a face inferior muito convexa; uma fileira de cerdas inferior, continuando pelo pólex até sua extremidade; grânulos na porção interna da margem superior; dedos longos e entrecruzados na porção distal; desprovido de hiato; pólex retilíneo, em nível mais elevado que a parte mais baixa da face inferior da palma, adelgaçando-se regularmente até o ápice; margem cortante denteada, com 6 dentes grandes regularmente espaçados, ladeados por duas fileiras de cerdas, uma externa e outra interna, outra fileira de cerdas na face externa, paralela à que vem da palma; grânulos na margem inferior próximo à palma; dáctilo aproximadamente retilíneo; extremidade aguda e encurvada para baixo; duas fileiras de cerdas, uma na margem superior e outra na face externa, paralela à margem superior; margem cortante denteada.

Quelípodo menor levemente inclinado para baixo, com dedos mais longos e 
finos, maiores que a palma; extremidades dos dedos agudas e encurvadas; dáctilo com cerca de sete dentes grandes regularmente espaçados, margem superior com cerdas; pólex com seis dentes regularmente espaçados, com uma fileira de grânulos prolongando-se até a palma, onde tornam-se maiores e mais densos.

Quelípodos da fềmea semelhantes ao quelípodo menor do macho; palma com uma fileira de grânulos prolongando-se até o pólex onde tornam-se mais agudos e densos; metade distal dos dedos com cerca de quatro dentes agudos.

Patas ambulatórias com cerdas; quatro fileiras de cerdas nas patas do primeiro ao terceiro pares, principalmente no própodo e dáctilo; quarto par apenas com duas fileiras de cerdas, uma superior e outra inferior; dáctilo do quarto par achatado lateralmente, levemente encurvado para baixo e para trás, em vista dorsal; dáctilo das outras patas levemente achatados dorso-ventralmente; mero levemente granulado na porção inferior.

Esterno alargado, liso; presença de uma placa suplementar entre o sétimo e oitavo esternitos; margem lateral externa da sutura entre o segundo e terceiro esternitos com uma fissura de cada lado, aberta e pouco profunda.

Abdômen do macho liso, largo; primeiro segmento mais largo que o segundo; terceiro ao quinto fusionados e com as margens sinuosas; terceiro segmento o mais largo, com bordo lateral arredondado. Abdômen da fêmea com sete segmentos, sendo o terceiro o mais largo.

Gonópodo do macho forte, levemente encurvado, afilado distalmente; pequenos espinhos na extremidade, mais numerosos na margem interna, indo até quase sua metade.

Dimensão. Macho holótipo: comprimento da carapaça $(5,25 \mathrm{~mm})$, largura da carapaça $(6,23 \mathrm{~mm})$.

Localidade tipo. Alagoas, Brasil; AKA\#170, 03-XII-1965, $10^{\circ} 33,5^{\prime} \mathrm{S}$ e $36^{\circ} 16,5^{\prime} \mathrm{W}, 50 \mathrm{~m} ; 22,30^{\circ} \mathrm{C}$ e $36,53 \mathrm{ppm}$; lama. 1993).

Outras referências. BRASIL: Ceará, Alagoas, Sergipe, Bahia (BARRETO et al.

Material examinado. O material estudado encontra-se na tabela IV.

Distribuição geográfica. Atlântico Ocidental: Brasil (Maranhão a Bahia).

Habitat. Os dados sobre o habitat encontram-se na tabela II.

Etimologia. O nome específico é uma homenagem ao destacado carcinólogo brasileiro, Prof. Dr. Gustavo Augusto Schmidt de Melo, pesquisador do Museu de Zoologia da Universidade de São Paulo.

Comentários. O exemplar proveniente do Maranhão (MZUSP8562), está com os dentes mais gastos que os outros exemplares, das demais localidades.

\section{DISCUSSÃO}

COELHO et al. (1980, 1986), BARRETO (1991, 1993), citam a presença de uma espécie de Chasmocarcinus não descrita, a sp B, no litoral brasileiro. A análise dos espécimens estudados por estes autores, revelou que se tratava na realidade de exemplares de $C$. peresi Rodriguez da Costa.

Revta bras. Zool. 15 (3): 799 - 814, 1998 
Levando em conta a angulosidade da margem interna do carpo dos quelípodos, as espécies do Oceano Atlântico podem ser divididas em 2 grupos: as que possuem o ângulo interno do carpo com espinho ou dente ( $C$. hirsutipes sp.n., $C$. mississipiensis Rathbun, C. obliquus Rathbun, C. rathbuni Bouvier e C. typicus Rathbun) e as que o possuem arredondado (C. arcuatus sp.n., C. chacei Felder \& Rabalais, C. cylindricus Rathbun, C. meloi sp.n. e C. peresi Rodrigues da Costa).

Das espécies que possuem espinho ou dente no carpo dos quelípodos, $C$. hirsutipes distingue-se principalmente por sua pelugem bastante típica, sendo bastante densa e concentrada na margem inferior do primeiro par de patas ambulatórias.

No que diz respeito às espécies que não possuem espinho ou dente no ângulo interno do carpo dos quelípodos, $C$. chacei é a única que não possui a carena ântero-lateral da carapaça, sendo esta bem definida em C. arcuatus, C. cylindricus, C. meloi e C. peresi; destas apenas C. peresi possui a carena sub-orbital bem definida, que dá a impressão que sua órbita cerca duas áreas distintas. C. meloi, difere entre outros aspectos, pela sua fronte quase reta, ao contrário da fronte bilobada de $C$. arcuatus e $C$. cylindricus; $C$. arcuatus é bem caracterizada principalmente pela quela maior dos machos maduros possuírem os dedos bastante arqueados e a superfície externa da palma erodida.

Observou-se em $C$. arcuatus, uma variação na morfologia do quelípodo maior do macho, representado principalmente pelo aumento do arqueamento dos dedos e consequentemente o hiato entre os memos, e redução do tamanho dos dentes na margem cortante, possivelmente causados pelo aumento da maturidade sexual; porém esses processos dão-se de forma gradativa nas diferentes fases de desenvolvimento, fato este comprovado também por GARTH (1940) em C. longipes do Oceano Pacífico. Segundo WARNER (1977) esta variação, observada em certos caranguejos, está relacionada com o incremento da maturidade sexual, podendo estas mundanças darem de forma abrupta ou suave. Esta variação encontrada sobretudo nos dedos do quelípodo maior de $C$. arcuatus não está relacionada ao seu tamanho, pois alguns indivíduos com tamanhos semelhantes, tinham quelas em diferentes padrões morfológicos.

FELDER \& RABALAIS (1986) citam a presença de um esporão córneo na margem inferior do dáctilo do último par de patas nas espécies da região do Golfo do México, porém esta estrutura não foi encontrada em nenhuma das espécies estudadas.

\section{REFERÊNCIAS BIBLIOGRÁFICAS}

Barreto, A.V.; P.A. Coelho; M. Ramos-Porto \& M.F.A. Torres. 1991. Distribuição batimétrica dos Brachyura (Crustacea, Decapoda) na plataforma continental Norte e Nordeste do Brasil. Trab. Oceanogr. Univ. Fed. Pernambuco 22: 291-303.

- 1993. Distribuição geográfica dos Brachyura (Crustacea, Decapoda) coletados na plataforma continental do Norte e Nordeste do Brasil. Revta bras. Zool. 10 (4): 641-656. 
BouVIER, E.L. 1917. Goneplacidés et pinnothéridés nouveaux recueillis au cours des campagnes américaines du "Hassler" et du "Blake". Bull. Mus. Natn. Hist. Nat. Paris 23 (1-7): 391-398.

Coelho, P.A. \& M.L. Koening. 1980. Biogeografia e bionomia dos crustáceos decápodos do litoral equatorial brasileiro. Trab. Oceanogr. Univ. Fed. Pernambuco 15: 7-138.

Coelho, P.A; M. Ramos-Porto \& T.C.S. CALAdo. 1986. Litoral do Rio Grande do Norte. Decapoda. Cad. Ômega Univ. Fed. Rural Pernambuco 2: 79-105.

FELDER, D.L. \& N.N. RABALAIS. 1986. The genera Chasmocarcinus Rathbun and Speocarcinus Stimpson on the continental shelf of the Gulf of Mexico, Whit description of the new species (Decapoda: Brachyura: Goneplacidae). Jour. Crust. Biol. 6 (3): 547-575.

GARTH, J.S. 1940. Some new species of brachyuran crabs from Mexico and the Central and South American Mainland. Alan Hanc. Pac. Exp. 5 (3): 53-127.

RAthBun, M.J. 1898a. The Brachyura of the biological expedition to the Florida Keys and the Bahamas in 1893. Bull. Lab. Nat. Hist. St. Univ. Iowa. 4 (3): 250-294.

. 1898b. The Brachyura collected by the U.S. Fish Commission Steamer "Albatross" on the voyage from Norfolk, Virginia to San Francisco, California, 1877-1888. Proc. U.S. Nat. Mus. 21: 567-616.

- 1900. Results of the Branner-Agassiz Expedition to Brazil. I. The Decapod and Stomatopod Crustacea. Proc. Wash. Acad. Sci. 2: 133-156.

. 1931. Two new crabs from the Gulf of Mexico. Proc. Biol. Soc. Wash. 44: 71-71.

RoDRIGUES DA CosTA, H. 1968. Crustacea Brachyura récoltés par les draguages de la "Calypso" sur les cotes brésiliennes (1962). Bull. Rec. Trav. St. Mar. End. 43 (59): 333-342.

WARNER, G. F. 1977. The biology of crabs. London, Van Nostrand Reinhold, 238p.

Recebido em 02.V.1997; aceito em 28.VIII.1998. 